\title{
Risk of severe driver injury by driving with psychoactive substances
}

Hels, Tove; Lyckegaard, Allan; Simonsen, Kirsten Wiese; Steentoft, Anni; Bernhoft, Inger Marie

Published in:

Accident Analysis \& Prevention

DOI:

10.1016/j.aap.2013.06.003

Publication date:

2013

Document version

Early version, also known as pre-print

Citation for published version (APA):

Hels, T., Lyckegaard, A., Simonsen, K. W., Steentoft, A., \& Bernhoft, I. M. (2013). Risk of severe driver injury by driving with psychoactive substances. Accident Analysis \& Prevention, 59, 346-356.

https://doi.org/10.1016/j.aap.2013.06.003 


\section{Accepted Manuscript}

Title: Risk of severe driver injury by driving with psychoactive substances

Author: Tove Hels Allan Lyckegaard Kirsten Wiese Simonsen Anni Steentoft Inger Marie Bernhoft<ce:footnote id="fn1"><ce:note-para id="npar0035">1Tel.: +45 452565

00; fax: +45 459365

$33</$ ce:note-para $></$ ce:footnote $><$ ce:footnote

id="fn2"><ce:note-para id="npar0040">2Tel: +45 353261

04; Fax: +45 353260 85</ce:note-para></ce:footnote>

PII:

S0001-4575(13)00231-5

DOI: http://dx.doi.org/doi:10.1016/j.aap.2013.06.003

Reference:

AAP 3180

To appear in:

Accident Analysis and Prevention

Received date:

$2-10-2012$

Revised date:

29-5-2013

Accepted date:

$1-6-2013$

Please cite this article as: Hels, T., Lyckegaard, A., Simonsen, K.W., Steentoft, A., Bernhoft, I.M., Risk of severe driver injury by driving with psychoactive substances, Accident Analysis and Prevention (2013), http://dx.doi.org/10.1016/j.aap.2013.06.003

This is a PDF file of an unedited manuscript that has been accepted for publication. As a service to our customers we are providing this early version of the manuscript. The manuscript will undergo copyediting, typesetting, and review of the resulting proof before it is published in its final form. Please note that during the production process errors may be discovered which could affect the content, and all legal disclaimers that apply to the journal pertain. 
Risk of severe driver injury by driving with psychoactive substances

Tove Hels ${ }^{\mathrm{a},}{ }^{*}$, Allan Lyckegaard $^{\mathrm{a}}$, Kirsten Wiese Simonsen ${ }^{\mathrm{b}}$, Anni Steentoft ${ }^{\mathrm{b}}$, Inger Marie Bernhoft ${ }^{\mathrm{a}}$

${ }^{a}$ Technical University of Denmark, Department of Transport, Bygningstorvet 116B, DK-2800 Lyngby,

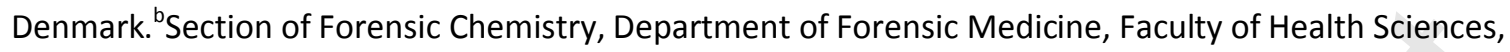
University of Copenhagen, Frederik V's Vej 11, 3., DK-2100 Copenhagen, Denmark.

* Corresponding author. Tel.: +45 452565 00; fax: +4545936533.

E-mail addresses: ths@transport.dtu.dk (T. Hels), ally@transport.dtu.dk (A. Lyckegaard), kirsten.wiese@forensic.ku.dk (K.W. Simonsen), anste@mail.tele.dk (A. Steentoft), imb@transport.dtu.dk (I.M. Bernhoft).

${ }^{a}$ Tel.: +45 452565 00; fax: +45 45936533 .

${ }^{\mathrm{b}}$ Tel: +45 353261 04; fax: +4535326085.

\section{Abstract}

Driving with alcohol and other psychoactive substances imposes an increased risk of severe injury accidents. In a population-based case-control design, the relative risks of severe driver injury (MAIS $\geq 2$ ) by driving with ten substance groups were approximated by odds ratios (alcohol, amphetamines, benzoylecgonine, cocaine, cannabis, illicit opiates, benzodiazepines and Z-drugs, i.e. zolpidem and zopiclone, medicinal opioids, alcohol-drug combinations and drug-drug combinations). Data from six countries were included in the study: Belgium, Denmark, Finland, Italy, Lithuania and the Netherlands. Case samples $(N=2,490)$ were collected from severely injured drivers of passenger cars or vans in selected hospitals in various regions of the countries. Control samples $(\mathrm{N}=15,832)$ were sampled in a uniform sampling scheme stratified according to country, time, road type and season. Relative risks were approximated by odds ratios and calculated by logistic regression. The estimates were adjusted for age, gender and country.

The highest risk of the driver being severely injured was associated with driving positive for high concentrations of alcohol $(\geq 0.8 \mathrm{~g} / \mathrm{L})$, alone or in combination with other psychoactive substances. For alcohol, risk increased exponentially with blood alcohol concentration (BAC). The second most risky category contained various drug-drug combinations, amphetamines and medicinal opioids. Medium increased risk was associated with medium sized BACs (at or above $0.5 \mathrm{~g} / \mathrm{L}$, below $0.8 \mathrm{~g} / \mathrm{L}$ ) and benzoylecgonine. The least risky drug seemed to be cannabis and benzodiazepines and Z-drugs.

For male drivers, the risk of being severely injured by driving with any of the psychoactive substances was about $65 \%$ of that of female drivers. For each of the substance groups there was a decrease in the risk of severe driver injury with increasing age.

It is concluded that among psychoactive substances alcohol still poses the largest problem in terms of driver risk of getting injured.

Keywords: driving under the influence, driver injury risk, road accident, case-control design 


\section{Introduction}

It is estimated that alcohol is responsible for $25 \%$ of the annual road fatalities in Europe, and that at least 10,000 people are killed in alcohol-related road accidents in the EU each year (Commission of the European Communities, 2006, SafetyNet, 2009). An equivalent estimate for drugs has not been published, but the incidence of drugs among drivers injured or killed in road accidents has been studied, and this incidence has been reported to fall in the range of $14 \%$ to $17 \%$ (OECD, 2010), well above the prevalence of drugs among drivers in general (OECD, 2010). This does not necessarily mean that drugs are responsible for all these accidents, but it is an indication that there is a relation between the two.

Driving when positive for alcohol affects driving performance (driving skills) and driving behaviour. In two publications, Moskowitz and Robinson (1987) and Moskowitz and Fiorentino (2000) systematically reviewed papers analysing the effect of Blood Alcohol Concentration (BAC) on driving performance (driving skills). Moskowitz and Robinson (1987) summarized 177 studies and concluded that '...there appears no lower BAC below which impairment cannot be said to exist.' In a similar set up, Moskowitz and Fiorentino (2000) reviewed 112 papers and concluded that impairment begins with any departure from zero BAC, and by $0.5 \mathrm{~g} / \mathrm{L}$ the majority of studies report impairment. Krüger (1993) in his review concluded that social and controlled behaviours (involving a greater mental workload) are impaired at the lowest BAC (0.30-0.49 g/L) whereas automatic behaviours (involving less mental workload) are not impaired until $0.5 \mathrm{~g} / \mathrm{L}$. Evans (2004) studied driving behaviour after alcohol intake and concluded that at a BAC of $0.5 \mathrm{~g} / \mathrm{L}$ judgement is altered, and the person is less inhibited.

Whereas the above studies treat the effect of alcohol on single human factors separately, an epidemiological study is designed to assess the overall increased risk of getting involved in an accident/getting injured or killed when driving positive for alcohol. By far the most cited of the studies is the Grand Rapids study by Borkenstein et al. (1974).

The fitness to drive while positive for psychoactive stimulants is not entirely clear: a meta-analysis of experimental studies of the effect of therapeutic doses of amphetamines and cocaine (that have stimulating effect on mental and physical performance (OECD, 2010)) found no negative effects on the fitness to drive (Berghaus et al., 2011); yet in an epidemiological study from Norway, the odds ratio of getting killed or severely injured when positive for amphetamines was 47.8 (Assum et al., 2005), thus very far from being harmless. In a recent meta-analysis on the relative risk of injury accidents associated with the use of drugs, Elvik (2012) found insignificant effects of the use of benzodiazepines, cannabis, cocaine and zopiclone, whereas the use of amphetamine and opiates was associated with significantly elevated risks (odds ratios of 6.19 and 1.89 , respectively).

The purpose of the present study was to assess the overall driver risk of being severely injured by driving with alcohol and/or other psychoactive substances. Psychoactive substances suspected to influence driving the most were included in the study (Simonsen et al., 2013). Benzodiazepines, Z-drugs and opioids make up most of the psychoactive medicines suspected to influence driving; thus several benzodiazepines, zolpidem, zopiclone, codeine, methadone and tramadol were included in the group of medicinal drugs while illicit drugs consisted of morphine (heroin), amphetamines, cocaine and cannabis. Data were collected in six countries in different parts of Europe according to the same protocol. This study has enough data to assess injury risk for less prevalent psychoactive substances as well as for the combination of alcohol and other 
psychoactive substances. Moreover, data allow assessing relations between severe driver injury risk and driving while positive for different concentrations of alcohol. 


\section{Methodology}

\subsection{Data collection}

The driver risk of being severely injured by driving with psychoactive substances was assessed in a population-based case-control design in six countries: Belgium (BE), Denmark (DK), Finland (FI), Italy (IT), Lithuania (LT) and the Netherlands (NL). The case sample consisted of blood specimens from drivers of passenger cars or vans (up to $3,500 \mathrm{~kg}$ ) who were severely injured (MAIS $\geq 2$ or equivalent, cf. Hels et al. (2011)). The MAIS scale runs from 1-6, with a score of 1 indicating minor injury in road accidents and 6 indicating death with four in-between stages: moderate, severe, serious and critical injury (Garthe et al., 1999). The control sample consisted of specimens of oral fluid/blood from drivers of passenger cars or vans who were stopped randomly on main urban and rural roads at selected sites and times $(N=15,832)$. In Table 1 the distribution of samples over the participating countries is shown. Case samples $(N=2,490)$ consisted of blood samples from all severely injured car/van drivers in trauma centre(s) of selected hospitals in various regions of the country. Information on the driver was collected (age and gender), and a blood sample was taken for subsequent toxicological analysis. Control samples were collected in the catchment areas of the trauma centre(s) where case samples were collected. Case and control sample regions are shown in Table 1.

$<$ TABLE 1 HERE >

In a population case control design, cases and controls need to match on a population level. Along this line two questions were asked:

1. In the case that a country had a higher number of road side survey regions (RSSR) than hospital survey regions (HSR) - true for DK, FI, IT and NL - it was tested ( $\chi^{2}$-tests) if age and gender distributions of the sampled drivers were significantly different in the RSSR that were matched by a HSR and the RSSR that were not matched by a HSR. The results of these tests are presented in Table 2. If either age, gender or both distributions differed significantly, the RSSRs that were not matched by HSRs were not included in the risk calculations. If distributions did not differ, data from the unmatched RSSRs were included.

2. In the case that a country had one or more HSR(s) that extended geographically beyond the RSSR(s) - true for DK - it was tested ( $\chi^{2}$-tests) whether there was a significant difference between the injury score distribution of the sampled injured driving population inside and outside of the RSSR(s). The results of these tests are presented in Table 3. This answers the question if the injured sampled population inside and outside of the road side survey area was injured to the same degree.

\section{$<$ TABLE 2 HERE $>$}

\section{$<$ TABLE 3 HERE $>$}

Control samples were collected in a systematic way, covering a variety of research locations as well as all times of the day, week and year (Table 4). It was the intention that the survey sample should be 
representative of traffic on all roads at all times. To this aim, eight sample periods covering the whole week were defined. In all countries, the controls were sampled over all eight time periods and subsequently, the data for each driver in the road side sample were weighted by the traffic fraction of the general driving population in the specific time period and country where the driver was stopped as recommended by Mathijssen and Houwing (2005). This way, data were weighted to represent general traffic. For actual weighting factors in different countries and time periods, we refer to Hels et al. (2011).

\section{$<$ TABLE 4 HERE $>$}

Drivers were tested for alcohol and drugs in a uniform way. For more information on the sampling procedure of controls, we refer to Houwing et al. (2011). Collection of control samples was carried out in 2008-2009 (BE, DK, IT, LT) and 2007-2009 (FI, NL). Collection of case samples was carried out in 2008-2010 (BE, FI, LT, NL), 2007-2010 (DK) and 2008-2009 (IT).

Following legal regulations, participation in the alcohol breath test at the roadside was mandatory, whereas the drug test (sample of oral fluid and/or blood) was voluntary. This leads to a question of potential nonresponse bias of control samples (Berghaus et al., 2007). Non-response bias occurs in the case that drivers who refuse to give a sample differ from those who do not with regard to drug use. Non-response in each participating country is shown in Table 5. Data were analysed for differences between respondents and non-respondents. In the Belgian data set (non-response rate (NRR): 52\%), there was no significant difference in BAC for respondents and non-respondents which indicates no serious non-response bias (Van der Linden et al., 2011). In the Finnish data set (NRR: 48\%) most of the non-respondents refused to participate when asked by the police. At this stage (before meeting the research team) they were not informed about the purpose of the study, only that it would take ten minutes. Thus, if the non-respondents were driving under the influence and afraid of being detected, they did not know the purpose of the study when refusing to participate. Moreover, the demographic profile of the respondents in the road side study was representative of the general Finnish driving population as described in a recently conducted study on the Finnish traffic distribution (Engblom et al., 2011; Ministry of Transport and Communications Finland). In the Lithuanian data set, NRR added up to $24 \%$. In Lithuania all the refusers were aged 18-31 and two thirds were women. This may indicate non-response bias, but all refusers were checked for signs of impairment, and none of them showed any (Caplinskiene et al., 2011). In Denmark, NRR was 5\%. There was no difference in gender and age between the respondents and the non-respondents (Hels et al., 2011). In the Netherlands (NRR: $5 \%$ ) male and younger drivers were overrepresented among the non-respondents. There was no difference in distribution of BAC levels between the respondents and the non-respondents which is an indication of no non-response bias. On the other hand, the self-reported use of psychoactive substances was higher for the non-response group (6.5\%) than for the response group (3.6\%) which indicates the probability of a non-response bias (Houwing et al., 2011). In Italy, the NRR was 0\% because of a legal regulation that allows mandatory body fluid collection by a physician assisted by a police officer (Ferrara et al., 2011). If drivers positive for psychoactive substances were more likely to refuse participation in the road side survey than others, this would lead to an overestimation of risk.

\section{$<$ TABLE 5 HERE $>$}


In Finland, the police allowed only an unknown fraction of the alcohol positives to be sampled, and in Italy, there was skewness in the driving population sampled towards drivers exhibiting signs of alcohol impairment. Consequently, negative samples and samples positive for alcohol or alcohol-drugs from these two countries were excluded from the calculations of OR for alcohol and alcohol-drugs.

Inclusion of the case drivers in the study was supposed to be done regardless of a suspicion of them being positive for psychoactive substances. In practice, there may have been sampling bias with patients more likely to be positive for psychoactive substances included more readily. If this were the case, it would result in an overestimation of risk. Another source of risk overestimation would be lack of information on any drugs administered after the accident but before the blood sample was taken (particularly medicinal opioids for pain relieving). It is not possible to estimate the size of a potential over- or underestimation of risk.

\subsection{Toxicological analysis}

As indicated, oral fluid and/or blood samples were collected at the road side (controls) and blood was sampled in the hospitals (cases). Blood samples were treated as follows:

- 5-10 $\mathrm{mL}$ whole blood collected in vacuum tubes containing sodium fluoride and potassium oxalate

- Transported at $4^{\circ} \mathrm{C}(\max .48 \mathrm{~h})$

- Stored in laboratory at $-20^{\circ} \mathrm{C}$

The criteria for oral fluid samples were:

- $1 \mathrm{~mL}$ oral fluid sampled using StatSure SalivaSampler ${ }^{\mathrm{TM}}$ (StatSure Diagnostic Systems, Framingham, MA, USA)

- Sampled according to guidelines by manufacturer

- Transported at $2-8^{\circ} \mathrm{C}$ (max. $\left.48 \mathrm{~h}\right)$

- Stored in laboratory at $-20^{\circ} \mathrm{C}$

An exception occurred in The Netherlands where the drivers spitted in a cup. However, it was shown (Langel et al., 2008) that the concentrations in oral fluid analysed by means of pure saliva (The Netherlands) did not differ from the concentrations analysed by means of the oral fluid from the StatSure SalivaSamplers ${ }^{\mathrm{TM}}$ that were diluted by the buffer in the sampler.

The StatSure SalivaSampler ${ }^{\mathrm{TM}}$ device was chosen among nine different oral fluid collection devices evaluated for the recovery and stability of drugs and suitability of the device for sample collection (Langel et al. 2008). As part of the project, new analysis methods were developed that enabled a simultaneous quantitation of a large number of substances from a small sample volume (Badawi et al., 2009; Langel et al., 2011).

All blood- and oral fluid samples were analysed by means of fully validated methods for the same number of substances in all countries. Proficiency test analyses of oral fluid and whole blood were carried out by all participating laboratories, resulting in a high quality of toxicological analyses in all countries. For more detailed descriptions of the toxicological procedures, cf. Badawi et al. (2009), Isalberti et al. (2011), and 
Langel et al. (2011). If both a blood and an oral fluid sample were taken, the toxicological analysis of the blood sample was used.

The following psychoactive substances were included in the analyses: alcohol, stimulants (amphetamines, cocaine), cannabis, narcotic analgesic (illicit opiates), sedatives (benzodiazepines, Z-drugs), narcotic analgesic (medicinal opioids). In total, 24 substances were analysed for in each participating country. The analytical findings were evaluated according to Table 6 . The groups were mutually exclusive. A sample positive for alcohol and cannabis was considered positive for alcohol-drugs but negative for both alcohol and cannabis. A sample positive for more substances within the same group (e.g. oxazepam and lorazepam) was not considered positive for multiple drugs, but for the substance group (in casu benzodiazepines) only. Samples categorised as negative were negative (i.e. below cut-off) for each of the tested substances.

In the body, cocaine metabolises to benzoylecgonine that is pharmacologically inactive. Nevertheless, benzoylecgonine was identified and interpreted as a sign of recent cocaine use.

\section{$<$ TABLE 6 HERE >}

Determining whether a subject was positive for a substance or not, was done by toxicological analyses of samples from both blood and oral fluid. Thus, to compare the saliva-positive subjects with the bloodpositive subjects it was crucial that equivalent cut-offs for blood and oral fluid were developed. These equivalent concentrations were developed by Verstraete et al. (2011) on the basis of samples from countries in which both blood and oral fluid was collected. The existence of equivalent concentrations partly solves the problem of comparing results based on two different specimens collected. The following results are based on concentrations of the substances in question that are equal to or exceed the abovementioned equivalent concentrations in blood and in oral fluid. For the exact values of the equivalent cutoffs, we refer to Verstraete et al. (2011). The equivalent cut-offs should be used with caution because in some cases they were determined from few studies (MDA, MDMA, 6-AM, and zopiclone) and no equivalent cut-off was determined for MDEA, therefore, the MDMA factor was used.

\subsection{Statistical analysis}

Under certain assumptions, relative risk (RR) can be approximated by odds ratio (OR) (Schmidt and Kohlmann, 2008). The assumptions are: 1) a low probability of severe driver injury among the drivers negative for all psychoactive substances (lower than $10 \%$, 'the rare disease assumption'), 2) a relatively low OR (about 4). In this study, relative risk of severe driver injury by driving with psychoactive substances was approximated by the $O R$, i.e. the driver odds of being severely injured by driving with one or more psychoactive substances relative to the driver odds of being severely injured by driving with no psychoactive substances (Hels et al., 2011). This approximation is further discussed in the discussion section.

OR's were calculated with logistic regression (Proc logistic, SAS 9.2). Logistic regression relates a number of independent variables to the probability of an event, in this case the driver probability of being severely injured by driving with psychoactive substances.

The logistic function is given by 


$$
P(y)=\frac{\exp (y)}{1+\exp (y)}
$$

Here, $P(y)$ denotes the driver probability of being severely injured by driving with psychoactive substances. The logit, $y$, is a linear expression of $\mathrm{x}$

$$
y=\beta_{\text {agegrp }} x_{\text {agegrp }}+\beta_{\text {gender }} x_{\text {gender }}+\beta_{\text {subst }} x_{\text {subst }}+\beta_{\text {country }} x_{\text {country }}+\beta_{0}
$$

where $x_{\text {agagry }}, x_{\text {gender }}, x_{\text {subst }}, x_{\text {zountry }}$ denote the four independent variables age group, gender, presence of a substance, and country, respectively (Table 7), and the $\beta^{\prime}$ s are the parameters estimated in the logistic regression. The four independent variables are all categorical.

By rearranging, the formula (1) can be put on the form of an odd

$$
\exp (\mathrm{y})=\frac{P(y)}{1-P(y)}
$$

Using (2), the odds ratio for severe driver injury given presence of substance can then be expressed as

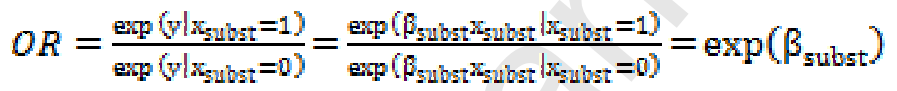

In a similar fashion, the odds ratios can be computed for severe driver injury given other independent variables.

The odds ratios have been calculated by means of logistic regression for the following substance groups: Alcohol, amphetamines, benzoylecgonine, cocaine, cannabis, illicit opiates, benzodiazepines and Zdrugs, as well as medicinal opioids. Two extra groups, alcohol-drugs and multiple drugs, were included.

Negative samples, that is samples for which no substances have been found in concentrations above or equal to the equivalent cut-off, made up the reference group irrespective of the substance group in question. The description of all modelling variables can be found in Table 7. Alcohol and/or other psychoactive substances represent the dependent variables - the presence of which is modelled by logistic regression. Age, gender and country are variables adjusted for in the model. Adjusting for variables in the model corresponds to keeping them constant, thus creating an everything-else-being-equal-scenario. For example, when adjusting for age, the effect of the drug on the probability of severe driver injury is isolated from the effect of age on injury probability. This gives comparable risk estimates for the various drugs.

$<$ TABLE 7 HERE> 


\section{Results}

Estimated driver odds ratios for being severely injured by driving with various psychoactive substance groups are shown in Table 8 and Figure 1. The estimated odds ratios are based on data from all six countries.

\section{$<$ TABLE 8 HERE >}

The most striking feature of Figure 1 and Table 8 is the exponential risk increase with the driver's increasing blood alcohol concentration. The adjusted odds ratio of a BAC of $0.1-0.49 \mathrm{~g} / \mathrm{L}$ was 1.3 and not significantly different from 1, whereas all BACs at or above 0.5 were associated with significant increases in risk relative to driving sober. The risk of driving with the highest BAC (at or above $1.2 \mathrm{~g} / \mathrm{L}$ ) was as high as 78 times higher than driving sober. The risks associated with driving with high BACs (at or above $0.8 \mathrm{~g} / \mathrm{L}$ ) were significantly higher than the risks of driving with illicit drugs (taken as one group) and medicinal drugs (taken as one group). The risk of severe driver injury by driving with a combination of alcohol and (any) other drug(s) was quite high, namely about 39 times higher than driving negative for all substances. This risk, too, was significantly higher than driving with the recorded illicit or medicinal drugs.

Among the illicit drugs amphetamine stood out as being associated with a higher risk than the other drugs, even though the confidence interval of the odds ratio is quite wide (Table 8). Cocaine and illicit opiates were associated with similar risks not significantly elevated, whereas cannabis was associated with a slightly elevated risk and benzoylecgonine with a somewhat higher risk.

Driving with medicinal opioids was associated with a significantly higher risk of severe driver injury than the substance group benzodiazepines and Z-drugs, i.e. 7.4 and 1.8, respectively - both however being significantly higher than 1 . Generally, the risks associated with driving with illicit drugs and medicinal drugs (taken as groups) were of similar magnitude with amphetamine and medicinal opioids standing out as exceptions associated with higher risks. Driving with various combinations of drugs was found to be significantly more risky than driving negative, but significantly less risky than driving with a combination of alcohol and other drugs.

$<$ TABLE 9 HERE $>$

When adjusted for national differences in odds ratios, gender related odds ratios were similar across the various substances (Table 9). For male drivers, the risk of being severely injured by driving with psychoactive substances was about $65 \%$ of that of female drivers. For each of the substance groups, this difference was highly significant. For each of the substance groups there was a decrease in the risk of severe driver injury with increasing age, but to different extents: The largest difference was for drivers positive for alcohol or a combination of alcohol and drugs. In these cases, driving with alcohol was more than five times more risky for young drivers (18-24 years old) than for older drivers (50+). The risk gradually decreased with age. For drivers aged 35-49 the risk was still significantly higher than the risk for those aged $50+$. For all other psychoactive substance groups the pattern was similar: the risk of severe driver injury by driving with the drug was about three times as high for the young drivers (18-24) than for the drivers aged 
50+. With increasing age this risk decreased, and for the drivers aged 35-49, the risk was not significantly different from that of the drivers aged $50+$.

< FIGURE 1 HERE > 


\section{Discussion}

An epidemiological study design reveals overall manifestations of risk factors, and this design is useful in assessing the role of risk factors in a large population (Berghaus et al., 2007). Case-control studies of drink and drug driving assess the risk in interaction with confounding factors such as risk taking behaviour, driving style, driving experience, fatigue, weather, road condition and choice of vehicle. Moreover, the dosage of alcohol/drug is not under the control of the researcher, but represents real life recreational/medical use. Case-control studies thus provide us with real life risks but with limited possibility to isolate the different confounding effects and control the dosage. To partly overcome the confounding effects, we have adjusted the risk estimates for age, gender and country, the first two to some extent being proxies for driving style. For all psychoactive substances analysed the estimated risk was higher for young drivers, lower for adult drivers and even lower for older drivers. Moreover, the estimated risk was lower for male than for female drivers. This modelling result is a combination of potentially different physiological effects of the drugs according to age and gender, age- and gender related vulnerability and a difference in driving style, risk willingness, vehicle choice and other factors proxied by age and gender.

The higher risk for young drivers of being severely injured compared to older drivers is not physiologically substantiated. Rather, it is probably founded in younger drivers' higher risk willingness when driving. The higher risk for female than male drivers seems paradoxical because female drivers are known to be less willing to take risk than male drivers (Evans, 2004), and this would logically lead to fewer female than male drivers being severely injured even when positive for psychoactive substances. There are, however, a number of possible reasons for this result: First, women have a smaller body volume to distribute any concentration of psychoactive substance than men do, and female drivers thus get more affected by a given substance amount. Second, it is well known that women are physically more vulnerable than men and suffer more severe injury at the same impact than men do (Evans, 2004). Thus, some of the accidents that resulted in severe injury for female drivers may have resulted in light or no injury for male drivers and consequently the accidents have not been included in the study. Third, women tend to drive smaller cars with less protection than men (Elvik and Vaa, 2004) which generally results in more severe injuries.

Odds ratios are always overestimations of relative risk, but using odds ratios gives the possibility of adjusting for confounding variables such as age, gender and country. Relative risk is most accurately approximated by odds ratio for low probabilities of severe driver injury among the drivers negative for all psychoactive substances (Schmidt and Kohlmann, 2008) and for small values of odds ratios. In this study, the relation between severely injured drivers and all drivers negative for psychoactive substances equals $(1177) /(1177+11073)=9.6 \%$ (Table 8). This is close to the maximum $10 \%$ recommended by Schmidt and Kohlman and means that for example an RR of 3 is approximated by an OR of 4 , and an RR of 5 is approximated by an OR of 9 .

The size of the risk estimates when driving positive for alcohol is a confirmation of the fact that alcohol is still the major road safety problem drug in terms of injury risk. The exponential increase in risk with increasing BAC found in this study complies with that of Borkenstein (1974), and the risk estimates fall in line with those of other epidemiological studies (Assum et al., 2005; Borkenstein, 1974; Hurst et al., 1994; Woratanarat et al., 2009). The high risk estimates of higher alcohol concentrations (at or above $0.8 \mathrm{~g} / \mathrm{L}$ ) 
compared to (most) drugs and medicine is difficult to explain. It may originate in one or a combination of the following: Physiological effects being different for various psychoactive substances with alcohol impairing safe driving more than the other substances; the psychoactive substances having been taken in different concentration equivalents and finally the fact that medicinal drugs presumably have been taken to remedy a medical condition that may in itself compromise safe driving. Following this logic, alcohol and other drugs taken for recreational purposes (amphetamines, cannabis, cocain and illicit opiates) would be associated with higher driver injury risk than medicinal drugs. This is true for alcohol and amphetamine, but not for the other illicit drugs and medicinal opioids. Controlled experiments are called for to assess doseresponse functions of intake of various drugs and medicines and the degree of compromise of safe driving. For example, Schnabel et al. (2010) conducted a meta-analysis of empirical studies of the effects of alcohol on safe driving, and their conclusion was that alcohol impairment functions are linear, while risk functions are exponential. Their explanation was that driving is a combination of subtasks that each may have a different impairment function, and that the result is a weighted aggregation of task-specific impairment functions.

Among the illicit drugs, amphetamine stood out as being associated with significantly higher driver injury risk than the others. In the literature, experimental results on driving with amphetamines indicate increase in driving performance (Gustavsen et al., 2006; Ramaekers, 2011). This is logical, since therapeutic doses of stimulants produce intense excitement and euphoria as well as alertness together with a decrease in reaction time (OECD, 2010) - effects that may improve psychomotor skills to a certain extent (Gustavsen et al., 2006). In real life settings, however, doses may be much higher than therapeutical, a situation that would be unethical to mimic in an experimental setting. Gustavsen et al. (2006) tested real-life amphetamine users and found a positive relationship between blood amphetamines concentration (BAmphC) and (police assessed) driving impairment. They found significantly increased impairment above BAmphCs of $270 \mathrm{ng} / \mathrm{mL}$.

In the present study, out of 17 control drivers exclusively positive for amphetamines (not in combination with alcohol or other drugs), only 7 gave a blood sample (the others gave an oral fluid sample). For these 7 drivers, the median BAmphC was 144 , and only 2 out of the 7 had BAmphCs exceeding $270 \mathrm{ng} / \mathrm{mL}$, whereas 5 out of the 7 had BAmphCs above that of therapeutic doses which would typically be up to $100 \mathrm{ng} / \mathrm{mL}$ (Hargutt et al., 2011). Out of 15 accident involved drivers exclusively positive for amphetamines the median BAmphC was $140 \mathrm{ng} / \mathrm{mL}$, and only 3 out of 15 drivers' BAmphCs exceeded $270 \mathrm{ng} / \mathrm{mL}$. Yet, 8 out of 15 drivers' BAmphC exceeded that of therapeutic doses. This material is numerically small but does not unambiguously support the hypothesis of far higher dosages in real life settings than in experiments. More likely, the higher risk in real life settings may be due to interaction between the substance and the risk taking behaviour so that users of amphetamines had a high affinity to risky situations - partly because they were under influence of the drug and partly because drivers who take amphetamines per se have a high risk affinity. Finally, the increased risk may be due to sleep deprivation after long waking periods induced by the amphetamines (Hargutt et al., 2011; OECD, 2010).

In the present study, the driver risk of being severely injured associated with driving with cocaine and illicit opiates was lower than the ones estimated by Dussault et al. (2002). However, in Dussault et al. (2002) the estimates were not adjusted for age and gender, and their case group consisted of killed drivers. Unadjusted cocaine risk estimates from this study complied well with the one in Dussault et al. (2002), but 
the illicit opiate risk estimate in this study was significantly above one which was not the case in Dussault et al. (2002). Movig et al. (2004) adjusted for age and gender, and their estimates are not significantly higher than one and thus comparable to the ones in this study. Thus, driving positive for illicit opiates and cocaine may be associated with an elevated risk for some drivers (young and adult drivers, female drivers), but with all drivers as one group the risk is not significantly higher than one. The higher odds ratio of benzoylecgonine compared to its parent compound, cocaine, may be caused by cocaine rapidly disappearing from the blood but still exerting an effect on driving performance (Simonsen et al., 2013).The driver injury risk estimated with driving positive for cannabis was just above one and complies well with several other studies where the risk varies from just around and not significantly different from one to around 3 (OECD, 2010). Medicinal opioids were associated with higher odds ratios than illicit opiates. This seems strange as the pharmacological profile is rather close for these two groups. This can possibly be explained by the few positive illicit opiate cases in both the case and control groups which makes the calculation of odds ratio for illicit opiates less reliable.

The risk of being severely injured by driving with alcohol combined with another psychoactive substance was generally higher than the risk of driving with alcohol or other drugs alone. This is in accordance with the fact that alcohol and (most) drugs like opioids, benzodiazepines and Z-drugs with a CNS depressant effect have a synergetic, not an additive effect. However, Veldstra et al. (2011) found in an experiment that ecstasy partly compensated for the effect of alcohol on driving performance when both drugs were given in combination. The combined risk of alcohol and other drugs was higher than the risk of other drugs combined with other drugs. This finding is consistent with the finding of Assum et al. (2005). The risk of combined use should not be generalised since the combined use of alcohol and other drugs and drugs with other drugs represents many different combinations of drugs.

\subsection{Strengths and limitations of the study}

In case-control studies a high number of both cases and controls is a prerequisite for obtaining reliable risk estimates. One clear strength of this study is the high number of control and case samples. The samples are distributed on six European countries, and for all we know, this is the first study on risk related to drink and drug driving performed simultaneously in six countries using a common study design. In each participating country, the number of positive cases was below five for one or more substance groups. Pooling the data thus improved the quality of the risk estimates considerably. It is highly questionable whether data from this study form a representative basis for common European risk estimates as far from all European countries participated in the study. However, it is fair to assume that the risk estimates represent the countries involved in this study.

This having been mentioned, there are drawbacks of the study as well: The high non-response rates in some countries may have affected the risk estimates. In the Methods section we have made it probable that among the controls there was no significant difference between the respondents and the nonrespondents, but even an insignificant difference may affect the exact value of the risk estimate. The nonrespondents in the control sample are likely to be positive for psychoactive substances, whereas in the case (hospital) sample, the hospital staff may be more likely to include patients believed to be positive. Thus, the non-respondents in both the control and the case sample may have led to the same direction - to an overestimation of risk. Our analyses suggest that the overestimation is of minor importance, and we 
conclude that the exact risk estimates must be handled with caution whereas the orders of magnitude of risk estimates are reliable.

In the study, not all existing opioids and benzodiazepines were analysed for, neither in the case nor in the control samples, so prevalence of these drugs are probably underestimated. As this is the case for both injured and control drivers, it is not possible to assess if it results in over- or underestimation of risk.

Collecting oral fluid at the road side has many advantages over blood and urine: it is fast, easy, noninvasive, and there is a lower risk of infection than by sampling blood (Langel, 2011). These are all factors that probably have contributed to lowering the non-response rate. In the hospitals, it was most suitable to collect blood samples due to the physical condition of some of the patients. Comparing substance concentrations from different body specimens is non-trivial. In a study parallel to this one, conversion factors were developed particularly for StatSure ${ }^{\mathrm{TM}}$ oral fluid and blood cut-off concentrations (Verstraete et al., 2011). The conversion factors can only be used for epidemiological studies and not for individual cases because of large individual variations. As mentioned earlier the conversion factors should be used with caution because in some cases they were determined from few studies (MDA, MDMA, 6-MAM, and zopiclone) and no conversion factor was determined for MDEA, therefore, the MDMA factor was used.

The equivalent cut-offs in blood and oral fluid are presented in Hels et al. (2011). Being able to convert cutoff values from one specimen to another allowed us to keep a high response rate for case as well as control samples.

\section{Conclusion}

Based on the results of this study it can be concluded that the highest driver risk of being severely injured by driving with psychoactive substances is associated with driving with high concentrations of alcohol in the blood $(\geq 0.8 \mathrm{~g} / \mathrm{L}$ ). Driving with high concentrations of alcohol in blood alone or in combination with other drugs was riskier than driving with any other drug. The second most risky category contained various drugdrug combinations, amphetamine and medicinal opioids. Medium increased risk was associated with alcohol in blood concentrations at or above $0.5 \mathrm{~g} / \mathrm{L}$ and below $0.8 \mathrm{~g} / \mathrm{L}$ and benzoylecgonine. The least risky drugs were cannabis and benzodiazepines and Z-drugs. Drugs associated with no significant risk increase were alcohol below $0.5 \mathrm{~g} / \mathrm{L}$, cocaine and illicit opiates.

Because of the sources of error, the main one being the non-response rate, the orders of magnitude of the risk estimates are reliable (e.g. alcohol all concentrations: 10, alcohol at or above $1.2 \mathrm{~g} / \mathrm{L}: 80$ ) whereas specific risk estimates (e.g. alcohol all concentrations: 9.79 , alcohol at or above $1.2 \mathrm{~g} / \mathrm{L:} \mathrm{77.76)} \mathrm{must} \mathrm{be}$ handled with caution. Due to the non-response biases described above the risks are probably slightly overestimated, but the orders of magnitude are reliable.

Even though this study included a large number of samples, risk estimates are associated with wide confidence intervals. A larger data set would allow for the estimation of more accurate risk estimates with narrower confidence intervals. Several research questions remain unsettled, particularly related to the risk of driving when positive for illegal opiates and medicinal opioids. 
In this study we have adjusted the risk estimates for the confounding variables driver age, gender and country. However, the epidemiological study design does not allow for adjusting for all risk related confounding variables such as driver risk taking behaviour, driving style, driving experience, fatigue, weather, road condition and choice of vehicle. We recommend that our study be followed up by experiments on driving performance when the driver is positive for various concentrations of psychoactive substances. It would be of particular interest to analyse experimentally dose-response relations between various psychoactive substances, driving performance, driver age and gender. 
Participating institutions in the project and disclaimer

Apart from the author institutions, the following institutions participated in the data collection:

Department of Clinical Chemistry, Microbiology and Immunology, Ghent University, Belgium; Institut Belge pour la Sécurité Routière, Belgium; National Institute for Health and Welfare, Alcohol and Drug Analytics Unit, Finland; State Forensic Medicine Service under the Ministry of Justice of the Republic of Lithuania; University of Padova, Italy and SWOV Institute for Road Safety Research, The Netherlands.

The paper has been produced under the Integrated Project DRiving Under the Influence of Drugs, Alcohol and medicines (DRUID) of the European Commission's (EC) 6th Framework Program and reflects only the authors' view. The EC is not liable for any use of the information contained therein.

\section{Acknowledgements}

The authors thank all the laboratory staff, hospital staff and research staff involved in the collection and analysis of blood samples as well as all the laboratory staff, police, and research staff involved in the collection and analysis of oral fluid samples. We are grateful for valuable discussions in an earlier phase with Prof. Mark Vollrath and Dr. Volker Hargutt. Finally, we thank three anonymous reviewers for their constructive comments on an earlier version of the manuscript. 


\section{References}

Assum, T., Mathijssen, M.P.M., Houwing, S., Buttress, S.C., Sexton, B., Tunbridge, R .J., Oliver, J., 2005. The prevalence of drug driving and relative risk estimations. A study conducted in The Netherlands, Norway and United Kingdom. Deliverable D-R4.2 of the $5 \mathrm{fp}$ project IMMORTAL. $95 \mathrm{pp}$.

Badawi, N., Simonsen, K.W., Steentoft, A., Bernhoft, I.M., Linnet, K., 2009. Simultaneous Screening and Quantification of 29 Drugs of Abuse in Oral Fluid by Solid-Phase Extraction and Ultraperformance LCMS/MS. Clin. Chem. 55, 2004-2018.

Berghaus, G., Ramaekers, J.G., Drummer, O.H., 2007. Demands on scientific studies in different fields of forensic medicine and forensic sciences. Traffic medicine - Impaired driver: Alcohol, drugs, diseases. Forensic Science International 165, 233-237.

Berghaus, G., Sticht, G., Grellner, W., Lenz, D., Naumann, T., Wiesenmüller, S ., 2011. Meta-analysis of empirical studies concerning the effects of medicines and illegal drugs including pharmacokinetics on safe driving. Deliverable 1.1.2b of 6fp DRUID. $701 \mathrm{pp}$.

Borkenstein, R.F., Crowther, R.F., Shumate, R.P., Ziel, W.B., Zylman, R., 1974: The role of the drinking driver in traffic accidents (The Grand Rapids Study). Blutalkohol, alcohol, drugs and behavior 11, 1-132.

Caplinskiene, M., Pauliukevicius, A., Minkuviene, Z., Stankute, V., 2011. Country report Lithuania. In: Prevalence of alcohol and other psychoactive substances in drivers in general traffic. Part 2: Country reports. Deliverable 2.2.3 in the 6fp DRUID, pp.123-139.

Commission of the European Communities, 2006. Communication from the Commission to the Council, the European Parliament, the European Economic and Social Commitee and the Committee of the Regions. An EU strategy to support Member States in reducing alcohol related harm. Brussels. 17 pp.

Dussault, C., Brault, M., Bouchard, J., Lemire, A.M., 2002: The Contribution of Alcohol and Other Drugs Among Fatally Injured Drivers in Quebec: Some Preliminary Results. In: Proceedings of the $16^{\text {th }}$ International Conference on Alcohol, Drugs and Traffic Safety. Québec: Société de l'Assurance Automobile du Québec.

Engblom, C., Langel, K., Blencowe, T., Räty, P., Pehrsson, A., Ihalainen, H., Lehtonen, L., Lillsunde, P., 2011. Country report Finland. In: Prevalence of alcohol and other psychoactive substances in drivers in general traffic. Part 2: Country reports. Deliverable 2.2.3 in the 6fp DRUID, pp.69-82.

Evans, L., 2004: Traffic Safety. Science Serving Society, Bloomfield Hills, Michigan.

Elvik, R. , Vaa, T., 2004: The Handbook of Road Safety Measures. Elsevier Ltd.

Ferrara, S.D., Favretto, D., Montisci, M., Vogliardi, S., Stocchero, G., Viel, G., Mazloum, R.E., Case, C., 2011. Country report Italy. In: Prevalence of alcohol and other psychoactive substances in drivers in general traffic. Part 2: Country reports. Deliverable 2.2.3 in the 6fp DRUID, pp.107-122.

Garthe,E., States, J.D., Mango, N.K., 1999. Abbreviated Injury Scale Unification: The Case for a Unified Injury System for Global Use, Journal of Trauma 47, 309-323. 
Gustavsen, I., Mørland, J., Bramness, J.G., 2006. Impairment related to blood amphetamine and/or metamphetamine concentrations in suspected drugged drivers. Accident Analysis and Prevention 38 (3), 490-495.

Hels, T., Bernhoft, I.M., Lyckegaard, A., Houwing, S., Hagenzieker, M., Legrand, S.-A., Isalberti, C., Van der Linden, T., Verstraete, A., 2011. Risk of injury by driving with alcohol and other drugs. Deliverable 2.3.5 in the 6FP DRUID, $73 \mathrm{pp}$.

Hels, T., Bernhoft I.M., Simonsen, K.W., Steentoft, A., 2011. Country report Denmark. In: Prevalence of alcohol and other psychoactive substances in drivers in general traffic. Part 2: Country reports. Deliverable 2.2.3 in the 6fp DRUID, pp.36-54.

Houwing S., Hagenzieker, M., Mathijssen R., Bernhoft, I.M., Hels, T., Janstrup, K., Van der Linden, T., Legrand, S.-A., Verstraete, A., 2011. Prevalence of alcohol and other psychoactive substances in drivers in general traffic. Part 1: General results and part 2: Country reports. Deliverable 2.2.3 in the 6FP DRUID, 386 p.

Hargutt, V., Krüger, H.-P., Knoche, A., 2011. Driving under the influence of alcohol, illicit drugs and medicines. Risk estimations from different methodological approaches. Deliverable 1.3.1 in the 6FP DRUID, $120 \mathrm{pp}$.

Hurst, P.M., Harte, D., Frith, W.J., 1994. The Grand Rapids Dip Revisited. Accident Analysis and Prevention 26 (5), 647-654.

Isalberti, C., Van der Linden, T., Legrand, S.-A., Verstraete, A., Bernhoft, I.M., Hels, T., Olesen, M.N., Houwing, S., Houtenbos, M., Mathijssen, R., 2011. Prevalence of alcohol and other psychoactive substances in injured and killed drivers. Part 1: Summary report, part 2: Country reports from hospital studies and part 3: Country reports from the studies on killed drivers. Deliverable 2.2.5 in the 6FP DRUID, 349 pp.

Krüger, H. -P., 1993. Effects of low alcohol dosages: A review of the literature. In: Alcohol, Drugs and Traffic Safety - T'92: Proceedings of the $12^{\text {th }}$ International Conference on Alcohol, Drugs and Traffic Safety, Cologne, 28 September - 2 October, 1992, Cologne, Verlag TUV Rheinland, pp.763-778.

Langel, K., Engblom, C., Pehrsson, A., Gunnar, T., Ariniemi, K., Lillsunde, P., 2008. Drug Testing in Oral Fluid Evaluation of Sample Collection Devices. Journal of Analytical Toxicology, 32, pp.397-401.

Langel, K., Gunnar,T., Ariniemi,K., Rajamäki, O., Lillsunde, P., 2011. A validated method for the detection and quantitation of 50 drugs of abuse and medicinal drugs in oral fluid by gas chromatography-mass spectrometry. Journal of Chromatography B, 879, 859-870.

Mathijssen, R., Houwing, S., 2005. The prevalence and relative risk of drink and drug driving in the Netherlands: a case-control study in the Tilburg police district. SWOV report no. R-2005-9. 55 pp.

Ministry of Transport and Communications Finland, Finnish National Road Administration, Finnish National Rail Administration and WSP Finland Ltd: Finnish National Travel Survey 2004-2005, www.hlt.fi.

Moskowitz H., Robinson C., 1987. Driving related skills impairment at low blood alcohol levels. In: Proceedings of the tenth international conference on alcohol, drugs and traffic safety, Amsterdam, Elsevier, pp.79-87. 
Moskowitz, H., Fiorentino, D., 2000. A Review of the Literature on the Effects of Low Doses of Alcohol on Driving-Related Skills. National Highway Traffic Safety Administration, Springfield, VA.

Movig, K.L.L., Mathijssen, M.P.M., Nagel, P.H.A., van Egmond, T., de Gier, J.J., Leufkens, H.G.M., Egberts, A.C.G., 2004: Psychoactive substance use and the risk of motor vehicle accidents. Accident Analysis and Prevention 36 (3), 631-636.

OECD, 2010. Drugs and Driving: Detection and deterrence, OECD publishing.

Ramaekers, J. (ed.) 2011. Effects of stimulant drugs on actual and simulated driving. Deliverable 1.2.1 in the 6FP DRUID, 165 pp.

Schmidt, C.O., Kohlmann, T., 2008. When to use the odds ratio or the relative risk? International Journal of Public Health 53, 165-167.

Scnhabel, E., Hargutt, V., Krüger, H.-P., 2010. Meta-analysis of empirical studies concerning the effects of alcohol on safe driving. Deliverable 1.1.2a in the 6FP DRUID, $166 \mathrm{pp}$.

SafetyNet, 2009: Alcohol, retrieved 2013:

http://ec.europa.eu/transport/road_safety/specialist/knowledge/pdf/alcohol.pdf

Simonsen, K.W., Steentoft, A., Bernhoft, I.M., Hels, T., Rasmussen B.S., Linnet K., 2013. Psychoactive substances in seriously injured drivers in Denmark. Forensic Toxicology 224, 44-50.

Van der Linden, T., Legrand, S.-A., Silverans, P., Verstraete, A., 2011. Country report Belgium. In: Prevalence of alcohol and other psychoactive substances in drivers in general traffic. Part 2: Country reports.

Deliverable 2.2.3 from the 6fp DRUID, pp.6-23.

Veldstra, J.L., Brookhuis K.A., de Waard, D., Molmans, B.H.W., Verstraete, A., Skopp, G., 2011. Effects of alcohol (BAC $0.5 \%$ ) and ecstasty (MDMA $100 \mathrm{mg}$ ) on (simulated) driving performance, driving related performance and traffic safety. In: Effects of stimulant drugs on actual and simulated driving. Deliverable $D$ 1.2.1 in the 6fp DRUID, pp.55-77.

Verstraete, A., Knoche, A., Jantos, R., Skopp, G., Gjerde, H., Vindenes, V., Langel, K., Lillsunde, P., 2011. Per se limits - Methods of defining cut off values for zero tolerance. Deliverable 1.4.2 in the 6FP DRUID, 68 pp.

Woratanarat, P., Ingsathit, A., Suriyawongpaisal, P., Rattanasiri, S., Chatchaipun, P., Wattayakorn, K., Anukarahanonta, T., 2009. Alcohol, illicit and non-illicit psychoactive drug use and road traffic injury in Thailand: A case-control study. Accident Analysis and Prevention 41 (3), 651-657. 


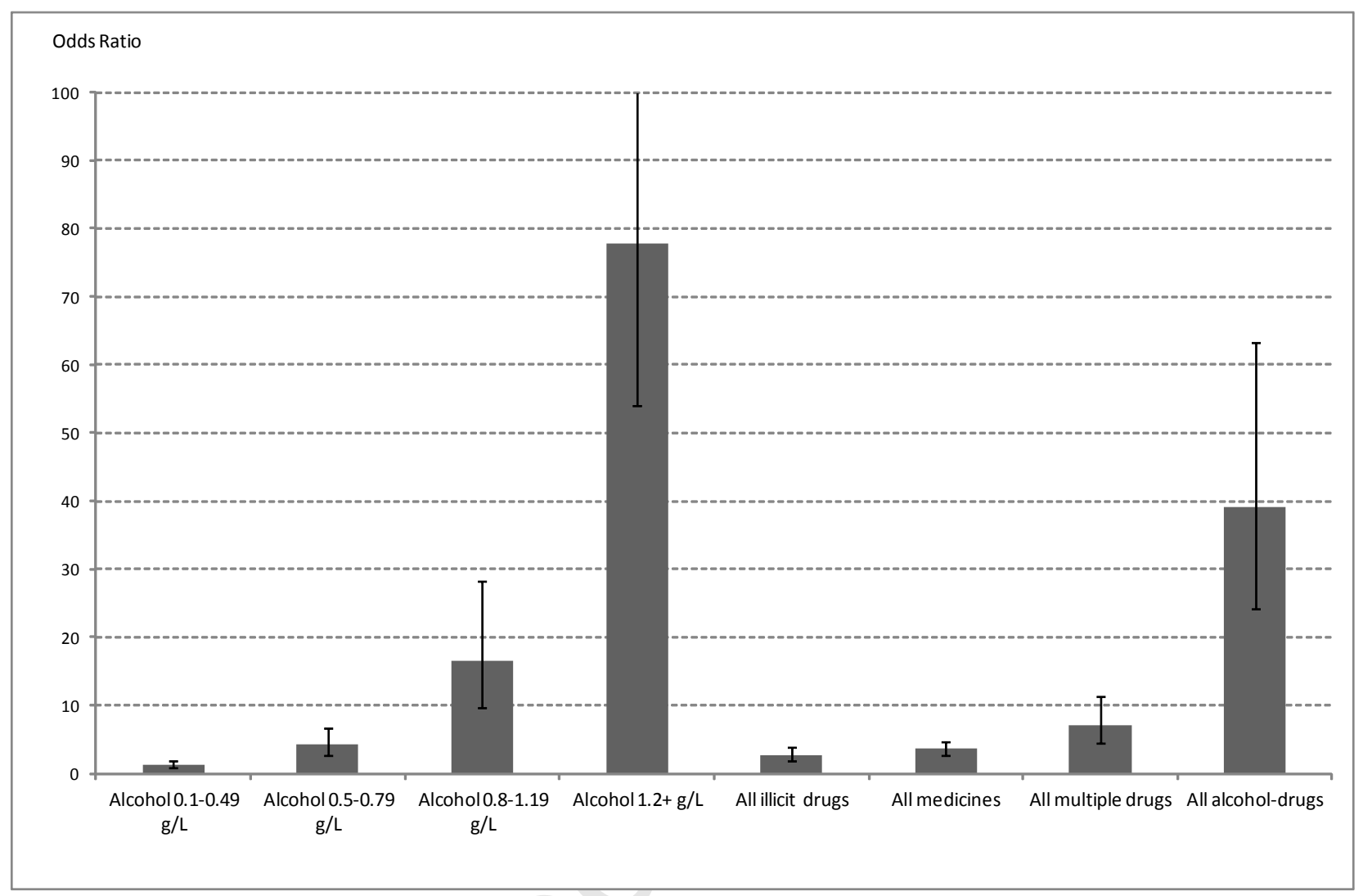

Figure 1. Odds ratios (OR) with $95 \% \mathrm{Cl}$ for severe driver injury by driving with psychoactive substances. OR's are adjusted for age, gender and country. 


\section{Table 1}

The number of case and control samples and sampling regions in each participating country.

\begin{tabular}{|c|c|c|c|c|c|c|}
\hline Country & & Cases & & & Controls & 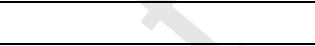 \\
\hline & $\mathrm{N}$ & Specimen & Sampling region & $\mathrm{N}$ & Specimen & Sampling region \\
\hline Belgium & 348 & Blood & $\begin{array}{l}\text { 1. Brussels } \\
\text { 2. Flanders } \\
\text { 3. Wallonia }\end{array}$ & 2,949 & $\begin{array}{l}\text { Oral fluid only }(199) / \text { blood } \\
\text { only }(0) \text { /both }(2,750)\end{array}$ & $\begin{array}{l}\text { 1. Brussels } \\
\text { 2. Flanders } \\
\text { 3. Wallonia }\end{array}$ \\
\hline Denmark & 839 & Blood & $\begin{array}{l}\text { 1. Ålborg and } \\
\text { Viborg } \\
\text { 2. Kolding, Vejle } \\
\text { and Odense }\end{array}$ & 3,002 & Oral fluid only & $\begin{array}{l}\text { 1. Ålborg and Viborg } \\
\text { 2. Kolding, Vejle and } \\
\text { Odense } \\
\text { 3. Roskilde }\end{array}$ \\
\hline Finland & 54 & Blood & 1. Uusimaa & 2,706 & Oral fluid only & $\begin{array}{l}\text { 1. Uusimaa } \\
\text { 2. Pohjois-Savo }\end{array}$ \\
\hline Italy & 676 & Blood & $\begin{array}{l}\text { 1. Padova } \\
\text { 2. Venezia } \\
\text { 4. Treviso } \\
\text { 5. Rovigo }\end{array}$ & 1,086 & $\begin{array}{l}\text { Oral fluid only (294)/blood } \\
\text { only (0)/both ( } 792)\end{array}$ & $\begin{array}{l}\text { 1. Padova } \\
\text { 2. Venezia } \\
\text { 3. Vicenza } \\
\text { 4. Treviso } \\
\text { 5. Rovigo }\end{array}$ \\
\hline Lithuania & 385 & Blood & $\begin{array}{l}\text { 1. Vilnius } \\
\text { 2. Kaunas } \\
\text { 3. Klaipeda } \\
\text { 4. Alytus }\end{array}$ & 1,267 & Blood only & $\begin{array}{l}\text { 1. Vilnius } \\
\text { 2. Kaunas } \\
\text { 3. Klaipeda } \\
\text { 4. Alytus }\end{array}$ \\
\hline $\begin{array}{l}\text { The } \\
\text { Nether- } \\
\text { lands }\end{array}$ & 188 & Blood & $\begin{array}{l}\text { 2. Tilburg (Tilburg } \\
\text { hospital) } \\
\text { 5. Twente } \\
\text { (Enchede hospital } \\
\text { only) } \\
\text { 6. Gelderland- } \\
\text { Zuid (Nijmegen } \\
\text { hospital only) }\end{array}$ & 4,822 & $\begin{array}{l}\text { Oral fluid only }(1,068) / \text { blood } \\
\text { only }(3,476) / \text { both }(278)\end{array}$ & $\begin{array}{l}\text { 1. Hollands-Midden } \\
\text { 2. Tilburg } \\
\text { 3. Amsterdam } \\
\text { Amstelland } \\
\text { 4. Groningen } \\
\text { 5. Twente } \\
\text { 6. Gelderland-Zuid }\end{array}$ \\
\hline Total & $\begin{array}{l}2,4 \\
90\end{array}$ & Blood & & 15,832 & $\begin{array}{l}\text { Oral fluid only }(7,269) / \text { blood } \\
\text { only }(4,743) \text { /both }(3,820)\end{array}$ & \\
\hline
\end{tabular}




\section{Table 2}

Test for homogeneity in age and gender distribution in road side survey regions.

\begin{tabular}{ll}
\hline Country & Is there a significant different age- and gender distribution in the road side sample regions \\
& (RSSR) that are matched by hospital survey regions (HSR) and the road side sample regions \\
that are not?
\end{tabular}




\section{Table 3}

Test for homogeneity in injury severity distribution in hospital survey regions.

\begin{tabular}{|c|c|}
\hline Country & $\begin{array}{l}\text { Is there a significant difference in distribution of injury severity score of the injured } \\
\text { population within and outside of the road side survey region(s)? }\end{array}$ \\
\hline Belgium & $\begin{array}{l}\text { HSRs matched RSSRs exactly by design. Consequently, all hospital study data were used in } \\
\text { relative risk calculations. }\end{array}$ \\
\hline Denmark & $\begin{array}{l}\text { HSR Kolding, Vejle and Odense (no. } 2 \text {, cf. Table } 1 \text { ) extended beyond the corresponding RSSR. } \\
\text { Trauma scores for all injured drivers in this region were grouped into four severity groups. } \\
\text { Subsequently, the scores were tested for homogeneity within and outside the RSSR. No } \\
\text { significant difference was found ( } \mathrm{N}=530, \mathrm{df}=3, \chi^{2}=7.03, \mathrm{p}=0.07 \text { ). Consequently, all hospital } \\
\text { data were included in the relative risk calculations. }\end{array}$ \\
\hline Finland & $\begin{array}{l}\text { Data from one of the RSSRs, Pohjois-Savo, were left out, cf. Table } 2 . \\
\text { The HSR of the Uusimaa region matched RSSR exactly by design. Consequently, all hospital } \\
\text { data from Uusimaa region were included in relative risk calculations. }\end{array}$ \\
\hline Italy & $\begin{array}{l}\text { Data from the fifth RSSR, Vicenza, were left out of the calculations, cf. Table } 2 \text {. } \\
\text { The other HSR matched RSSR exactly by design (Padova and Rovigo regions), or RSSRs were } \\
\text { larger than HSRs (Venezia and Treviso). Consequently, all hospital data from these four } \\
\text { regions were included in relative risk calculations. }\end{array}$ \\
\hline Lithuania & $\begin{array}{l}\text { HSRs matched RSSRs exactly by design. Consequently, all hospital study data were included in } \\
\text { relative risk calculations. }\end{array}$ \\
\hline The & In the Netherlands, three out of six RSSRs were matched by HSRs. In region no. 2, Tilburg, the \\
\hline Netherlands & $\begin{array}{l}\text { HSR was larger than the RSSR; in region no. 5, Twente, the HSR and the RSSR matched each } \\
\text { other quite well; and in region no. 6, Gelderland-Zuid, there was a certain overlap between } \\
\text { the two. Since the regions were not defined precisely, homogeneity tests could not be } \\
\text { carried out. Consequently, all hospital study data were used in relative risk calculations. }\end{array}$ \\
\hline
\end{tabular}




\section{Table 4}

Time schedule for road side sampling.

\begin{tabular}{llllll}
\hline \multicolumn{2}{c}{ Weekdays } & \multicolumn{2}{c}{ Weekend } \\
\hline 1 & Monday- Friday & $04: 00-09: 59$ & 5 & Saturday and Sunday & $04: 00-09: 59$ \\
2 & Monday - Friday & $10: 00-15: 59$ & 6 & Saturday and Sunday & $10: 00-15: 59$ \\
3 & Monday-Thursday & $16: 00-21: 59$ & 7 & Friday - Sunday & $16: 00-21: 59$ \\
4 & Monday - Thursday & $22: 00-23: 59$ & 8 & Friday - Sunday & 22:00-23:59 \\
\hline
\end{tabular}




\section{Table 5}

Non response percentage, cases and controls.

\begin{tabular}{|c|c|c|c|}
\hline Country & $\begin{array}{l}\text { Non } \\
\text { response } \\
\text { percentage, } \\
\text { drivers } \\
\text { (controls) }\end{array}$ & $\begin{array}{l}\text { Non } \\
\text { response } \\
\text { percentage, } \\
\text { injured } \\
\text { drivers } \\
\text { (cases) } \\
\end{array}$ & Reasons for non-response, cases \\
\hline Belgium & $52 \%$ & $5.4 \%$ & $\begin{array}{l}\text { For some drivers a patient form was filled in, but } \\
\text { they refused to give a blood sample for } \\
\text { toxicological analysis }\end{array}$ \\
\hline Denmark & $5 \%$ & $5 \%$ & $\begin{array}{l}\text { Blood sample or patient sheet went missing } \\
\text { For some drivers a patient form was available but } \\
\text { no blood sample; these drivers make up the non- } \\
\text { response percentage. }\end{array}$ \\
\hline Finland & $48 \%$ & $8.5 \%$ & No problems reported \\
\hline Italy & $0 \%$ & $0 \%$ & $\begin{array}{l}\text { Accident information from the police could not be } \\
\text { obtained }\end{array}$ \\
\hline Lithuania & $24 \%$ & $0 \%$ & No problems reported \\
\hline $\begin{array}{l}\text { The } \\
\text { Netherlands }\end{array}$ & $5 \%$ & Unknown & $\begin{array}{l}\text { Drug and alcohol intoxicated patients were less } \\
\text { likely to be blood sampled than sober patients }\end{array}$ \\
\hline
\end{tabular}




\section{Table 6}

Grouping of substances included in the analysis.

\begin{tabular}{|c|c|c|}
\hline Type & Group & Analytical findings \\
\hline Alcohol & Alcohol & ethanol \\
\hline Illicit & Amphetamines & amphetamine \\
\hline \multirow[t]{8}{*}{ Drugs } & & methamphetamine or methamphetamine + amphetamine \\
\hline & & MDMA* or MDMA + MDA** \\
\hline & & $\mathrm{MDEA}^{* * *}$ or MDEA + MDA \\
\hline & & MDA \\
\hline & Benzoylecgonine & benzoylecgonine \\
\hline & Cocaine & cocaine + benzoylecgonine or cocaine \\
\hline & $\mathrm{THC}$ & $\mathrm{THC}$ or $\mathrm{THC}+\mathrm{THCCOOH}$ \\
\hline & Illicit opiates & $\begin{array}{l}\text { 6-acetylmorphine or 6-AM + codeine or 6-AM + morphine or 6-AM + codeine + } \\
\text { morphine or (morphine + codeine and morphine }>=\text { codeine) }\end{array}$ \\
\hline \multirow[t]{12}{*}{ Medicinal drugs } & $\begin{array}{l}\text { Benzodiazepines } \\
\text { and Z-drugs }\end{array}$ & $\begin{array}{l}\text { diazepam or diazepam + nordiazepam or diazepam + oxazepam or diazepam + } \\
\text { nordiazepam + oxazepam }\end{array}$ \\
\hline & & nordiazepam or nordiazepam + oxazepam \\
\hline & & oxazepam \\
\hline & & $\begin{array}{l}\text { lorazepam } \\
\text { alprazolam }\end{array}$ \\
\hline & & flunitrazepam or flunitrazepam + 7-aminoflunitrazepam \\
\hline & & clonazepam or clonazepam + 7-aminoclonazepam \\
\hline & & zolpidem \\
\hline & & zopiclone \\
\hline & Medicinal & morphine \\
\hline & opioids & codeine or (codeine + morphine and codeine $>$ morphine) \\
\hline & & methadone \\
\hline & & tramadol \\
\hline Various & Alcohol-drugs & all combinations \\
\hline combinations & Multiple drugs & all combinations \\
\hline
\end{tabular}

*Methylenedioxy-methylamphetamine (ecstasy)

** Methylenedioxyamphetamine (ecstasy)

*** Methylenedioxyethylamphetamine 


\section{Table 7}

Variables in the odds ratio calculations.

\begin{tabular}{|c|c|c|}
\hline Variable & $\begin{array}{c}\text { Number } \\
\text { of } \\
\text { categories }\end{array}$ & Categories \\
\hline Age & 4 & $\begin{array}{l}18-24 \text { years of age } \\
25-34 \text { years of age } \\
35-49 \text { years of age } \\
50+\text { years of age }\end{array}$ \\
\hline Gender & 2 & $\begin{array}{l}\text { Male } \\
\text { Female }\end{array}$ \\
\hline Country & 6 & $\begin{array}{l}\text { Belgium } \\
\text { Denmark } \\
\text { Finland } \\
\text { Italy } \\
\text { Lithuania } \\
\text { The Netherlands }\end{array}$ \\
\hline Alcohol & 5 & $\begin{array}{l}<0.10 \mathrm{~g} / \mathrm{L} \text { (reference group) } \\
0.10-0.49 \mathrm{~g} / \mathrm{L} \\
0.50-0.79 \mathrm{~g} / \mathrm{L} \\
0.80-1.19 \mathrm{~g} / \mathrm{L} \\
1.20+\mathrm{g} / \mathrm{L}\end{array}$ \\
\hline $\begin{array}{l}\text { Drugs } \\
\text { - Amphetamines } \\
\text { - Benzoylegonine } \\
\text { - Cocaine } \\
\text { - Cannabis } \\
\text { - Illicit opiates } \\
\text { - Benzodiazepines and Z- } \\
\text { drugs } \\
\text { - Medicinal opioids } \\
\text { - Alcohol-drug(s) } \\
\text { - Multiple drugs }\end{array}$ & 2 & $\begin{array}{l}\text { Concentration below cut-off (i.e. negative, reference } \\
\text { group) } \\
\text { Positive (concentration above or equal to cut-off): } \\
\text { - positive for one drug: positive for one drug group only } \\
\text { - positive for alcohol-drug(s): positive for alcohol plus } \\
\text { one or more drugs } \\
\text { - positive for multiple drugs: positive for more than one } \\
\text { drug, but not for alcohol }\end{array}$ \\
\hline
\end{tabular}




\section{Table 8}

Odds ratios for severe driver injury by driving with psychoactive substances. Odds ratios in brackets are not significantly different from one $(P<0.05)$.

\begin{tabular}{|c|c|c|c|c|c|}
\hline Substance & $\mathbf{N}$ & Crude OR & 95\% C.I. & Adjusted** OR & 95\% C.I. \\
\hline & \multicolumn{5}{|l|}{ controls/ cases* } \\
\hline Negative (reference) & $11073 / 1177$ & 1.00 & & 1.00 & \\
\hline All alcohol concentrations & $557 / 345$ & 7.71 & $6.61-8.99$ & 9.79 & $8.18-11.72$ \\
\hline $0.1 \mathrm{~g} / \mathrm{L} \leq$ alcohol $<0.5 \mathrm{~g} / \mathrm{L}$ & $368 / 32$ & $(1.07)$ & $0.74-1.55$ & $(1.30)$ & $0.88-1.94$ \\
\hline $0.5 \mathrm{~g} / \mathrm{L} \leq$ alcohol $<0.8 \mathrm{~g} / \mathrm{L}$ & $90 / 30$ & 4.03 & $2.62-6.20$ & 4.18 & $2.58-6.77$ \\
\hline $0.8 \mathrm{~g} / \mathrm{L} \leq$ alcohol $<1.2 \mathrm{~g} / \mathrm{L}$ & $42 / 44$ & 14.27 & $8.91-22.84$ & 16.48 & $9.64-28.18$ \\
\hline Alcohol $\geq 1.2 \mathrm{~g} / \mathrm{L}$ & $57 / 239$ & 54.45 & $39.00-76.02$ & 77.76 & 54.11-111.74 \\
\hline All illicit drugs & $201 / 57$ & 2.89 & $2.13-3.91$ & 2.68 & $1.88-3.82$ \\
\hline Amphetamine & $17 / 15$ & 9.65 & $4.63-20.11$ & 14.15 & $5.82-34.42$ \\
\hline Benzoylecgonine & $20 / 9$ & 4.91 & $2.17-11.12$ & 3.88 & $1.41-10.68$ \\
\hline Cocaine & $18 / 7$ & 2.83 & $1.21-6.64$ & $(1.65)$ & $0.66-4.16$ \\
\hline Cannabis & $138 / 24$ & 1.84 & $1.18-2.87$ & 1.91 & $1.15-3.17$ \\
\hline Illicit opiates & $8 / 2$ & $(2.40)$ & $0.50-11.45$ & $(1.18)$ & $0.23-5.99$ \\
\hline $\begin{array}{l}\text { All medicines } \\
\text { Benzodiazepines and Z- }\end{array}$ & $215 / 101$ & 3.59 & $2.84-4.55$ & 3.60 & $2.74-4.74$ \\
\hline drugs & $142 / 34$ & 1.72 & $1.19-2.50$ & 1.77 & $1.16-2.69$ \\
\hline Medicinal opioids & $73 / 67$ & 8.00 & $5.73-11.18$ & 7.37 & $4.99-10.88$ \\
\hline $\begin{array}{l}\text { All alcohol-drug } \\
\text { combinations }\end{array}$ & $40 / 91$ & 32.74 & $21.16-50.66$ & 39.15 & $24.21-63.31$ \\
\hline $\begin{array}{l}\text { All multiple drug } \\
\text { combinations }\end{array}$ & $53 / 50$ & 8.67 & $5.85-12.85$ & 7.02 & $4.38-11.24$ \\
\hline
\end{tabular}

* Due to sampling skewness, negative samples and samples positive for alcohol or alcohol-drugs from Finland and Italy were excluded from the calculations of OR for alcohol and alcohol-drugs.

** Adjusted for age, gender and country. 


\section{Table 9}

Odds ratios for severe driver injury when driving positive for psychoactive substances by age and gender categories. Odds ratios in brackets are not significantly different from one $(P<0.05)$.

\begin{tabular}{|c|c|c|c|c|}
\hline Substance & Effect & & Adjusted* OR & 95\% C.I. \\
\hline \multirow[t]{4}{*}{ All alcohol concentrations } & Gender & Male vs. female & 0.67 & $0.59-0.76$ \\
\hline & Age & $18-24$ vs. $50+$ & 5.83 & 4.87-6.98 \\
\hline & & $25-34$ vs. $50+$ & 2.38 & $1.99-2.84$ \\
\hline & & $35-49$ vs. $50+$ & 1.34 & $1.13-1.59$ \\
\hline \multirow[t]{4}{*}{ Amphetamine } & Gender & Male vs. female & 0.65 & $0.58-0.74$ \\
\hline & Age & $18-24$ vs. $50+$ & 2.93 & $2.49-3.46$ \\
\hline & & $25-34$ vs. $50+$ & 1.32 & $1.12-1.55$ \\
\hline & & $35-49$ vs. $50+$ & $(0.92)$ & $0.79-1.07$ \\
\hline \multirow[t]{4}{*}{ Benzoylecgonine } & Gender & Male vs. female & 0.65 & $0.58-0.73$ \\
\hline & Age & $18-24$ vs. $50+$ & 2.91 & $2.47-3.43$ \\
\hline & & $25-34$ vs. $50+$ & 1.32 & $1.12-1.55$ \\
\hline & & $35-49$ vs. $50+$ & $(0.93)$ & $0.80-1.08$ \\
\hline \multirow[t]{4}{*}{ Cocaine } & Gender & Male vs. female & 0.65 & $0.58-0.73$ \\
\hline & Age & $18-24$ vs. $50+$ & 2.94 & $2.50-3.47$ \\
\hline & & $25-34$ vs. $50+$ & 1.31 & $1.11-1.54$ \\
\hline & & $35-49$ vs. $50+$ & $(0.92)$ & $0.79-1.07$ \\
\hline \multirow[t]{4}{*}{ Cannabis } & Gender & Male vs. female & 0.65 & $0.58-0.74$ \\
\hline & Age & $18-24$ vs. $50+$ & 2.96 & $2.51-3.49$ \\
\hline & & $25-34$ vs. $50+$ & 1.33 & $1.13-1.56$ \\
\hline & & $35-49$ vs. $50+$ & $(0.92)$ & $0.79-1.07$ \\
\hline \multirow[t]{4}{*}{ Illicit opiates } & Gender & Male vs. female & 0.65 & $0.58-0.73$ \\
\hline & Age & $18-24$ vs. $50+$ & 2.95 & $2.50-3.47$ \\
\hline & & $25-34$ vs. $50+$ & 1.31 & $1.12-1.55$ \\
\hline & & $35-49$ vs. $50+$ & $(0.92)$ & $0.79-1.08$ \\
\hline \multirow[t]{4}{*}{ Benzodiazepines and Z-drugs } & Gender & Male vs. female & 0.65 & $0.58-0.74$ \\
\hline & Age & $18-24$ vs. $50+$ & 2.88 & $2.45-3.39$ \\
\hline & & $25-34$ vs. $50+$ & 1.32 & $1.12-1.55$ \\
\hline & & $35-49$ vs. $50+$ & $(0.92)$ & $0.80-1.08$ \\
\hline \multirow[t]{4}{*}{ Medicinal opioids } & Gender & Male vs. female & 0.66 & $0.59-0.74$ \\
\hline & Age & $18-24$ vs. $50+$ & 2.98 & $2.53-3.51$ \\
\hline & & $25-34$ vs. $50+$ & 1.33 & 1.14-1.57 \\
\hline & & $35-49$ vs. $50+$ & $(0.94)$ & $0.80-1.09$ \\
\hline \multirow[t]{4}{*}{ All alcohol-drug combinations } & Gender & Male vs. female & 0.63 & $0.55-0.72$ \\
\hline & Age & $18-24$ vs. $50+$ & 5.32 & $4.40-6.43$ \\
\hline & & $25-34$ vs. $50+$ & 2.04 & $1.69-2.47$ \\
\hline & & $35-49$ vs. $50+$ & 1.24 & $1.04-1.49$ \\
\hline All multiple drug combinations & Gender & Male vs. female & 0.65 & $0.58-0.74$ \\
\hline
\end{tabular}


Age

$18-24$ vs. $50+$

2.92

2.48-3.44

25-34 vs. $50+$

1.34

$1.14-1.57$

$35-49$ vs. $50+$

(0.93)

$0.80-1.09$

*Adjusted for age, gender and country. Country not shown for reasons of brevity. 
Highlights

We estimated risk of serious road accident injury when driving under the influence

Risk of driving with alcohol and other drugs was estimated in a case-control design

Highest risk was associated with driving with high concentrations of alcohol

Other high-risk groups were amphetamine and combinations of alcohol and other drugs

Estimated risks were negatively correlated with age and higher for women than for men 